\title{
Research on Tool Cutting Performance and Turning Simulation
}

\author{
WEI Liao ${ }^{1,2}$ \\ ${ }^{1}$ Guangxi Radio and TV University, Nanning 530022, China \\ ${ }^{2}$ Sichuan University, Chengdu 610065, China
}

\begin{abstract}
In order to study the effect of pulse current treatment on tool cutting performance of cemented carbide, on the basis of cutting experiment, the cutting performance of tool was treated by different current density $\left(\mathrm{J}=5 \mathrm{~A} / \mathrm{mm}^{2}, 15 \mathrm{~A} / \mathrm{mm}^{2}\right.$ and $\left.35 \mathrm{~A} / \mathrm{mm}^{2}\right)$ processing and untreated tool was compared. The results showed that after the treatment of pulse current, when the current density $\mathrm{J}$ increases from $5 \mathrm{~A} / \mathrm{mm}^{2}$ to 35 $\mathrm{A} / \mathrm{mm}^{2}$, the hardness of small cylindrical sample and the transverse fracture strength of cuboid sample was improved than that untreated sample; the cutting performance increased 5.6\%, 8.2\% and $10.8 \%$ than that untreated tool, tool life has been improved. After the treatment of pulse current, pulse current provides the driving force for dislocation motion, strong driving force is more likely to make the dislocation multiplication and slip, high density dislocation cell is formed within the material, so that the mechanical properties increase significantly. The simulation study of turning processing based on finite element analysis software Deform 3D. The size distribution of cutting force was simulated, the simulation results and the test results were compared and analyzed, which provided guiding significance for the determination of process parameters
\end{abstract}

\section{Introduction}

The cutting tool can withstand higher temperature and mechanical shock during machining, which will cause the tool to wear, and the residual stresses will accelerate tool wear and influence the surface machining quality of the workpiece ${ }^{[1-3]}$.

The improvement of tool has been an important research topic in the whole machinery manufacturing industry. To fully excavate the cutting performance, reduce tool wear, improve the machining precision of the tool, is an important way to reduce production costs, ensure product quality and improve productivity ${ }^{[4-6]}$.

In recent years, pulsed current treatment as a new technology to improve the microstructure and properties of materials has the advantages of clean, high efficiency and low cost, which has attracted the attention of the material workers ${ }^{[7-9]}$. The pulsed current treatment has been reported in the field of materials electron plasticity, amorphous, crack healing and fatigue performance improvement ${ }^{[10-14]}$.

In this paper, the effect of pulse current treatment on microstructure and performance of cemented carbide was analyzed and studied, provide support for further systematic study the change law of tool cutting performance under the external field.

At the same time, due to the rapid development of computer technology and finite element theory, the finite element method has been widely used in the field of analytical machining. The simulation study of turning processing based on finite element analysis software Deform 3D. The size distribution of cutting force was simulated, the simulation results and the test results were compared and analyzed, which provided guiding significance for the determination of process parameters .

\section{Experiment}

The experimental objects are cemented carbide cylinder sample, rectangular specimens and cemented carbide tool, and the workpiece material is $45 \#$ hardened and tempered steels.

The sample was put into a self-made pulse current treatment device. The diagram of pulse current processing device was shown in Fig.1. In this experiment, the pulse current treatment (PCT) has three technics

(PCT-A, PCT-B and PCT-C), and parameters were shown in Table1. 


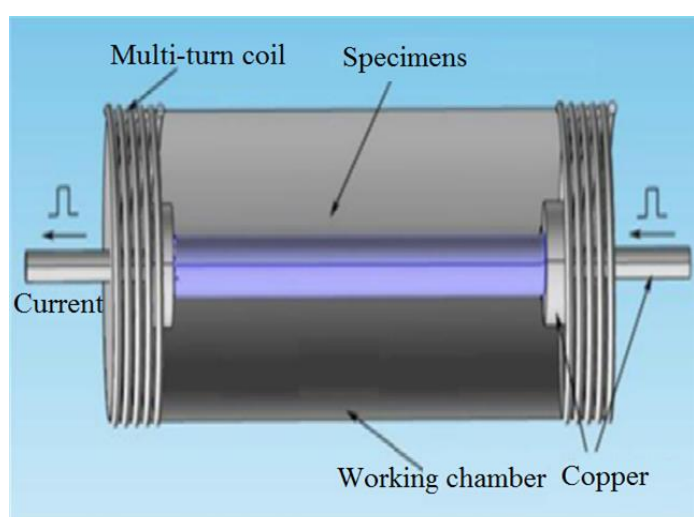

Fig.1 The diagram of pulse current processing device

Table 1 Current processing parameter

\begin{tabular}{cc}
\hline Technics & Current density $\left(\mathrm{A} / \mathrm{mm}^{2}\right)$ \\
\hline PCT-A & 5 \\
PCT-B & 15 \\
PCT-C & 35 \\
\hline
\end{tabular}

Then the experiment of turning excircle was done on the NC lathe by the unprocessed tool and the tool processed by pulse current treatment. During the experiment, the wear extent of flank surface was measured by image measuring instrument and the cutting force was measured by dynamometer. The microstructure of sample was observed by transmission electron microscope .

\section{Results and discussion}

\subsection{Effect of pulse current treatment on dislocation of cemented carbide}

Fig.2 showed the transmission electron microscope (TEM) photo of YG8 cemented carbide with untreated and pulse current treatment.

It can be seen from Fig.2a and Fig.2b that after pulse current treatment, compared with untreated sample, the number of dislocation in the sample was significantly increased, the dislocation cell and tangled dislocation structure appeared.

After the treatment of pulse current, pulse current provides the driving force for dislocation motion, strong driving force is more likely to make the dislocation multiplication and slip, high density dislocation cell is formed within the material, so that the dislocation density increase, it helps to improve the strength of materials, the mechanical properties increase significantly.
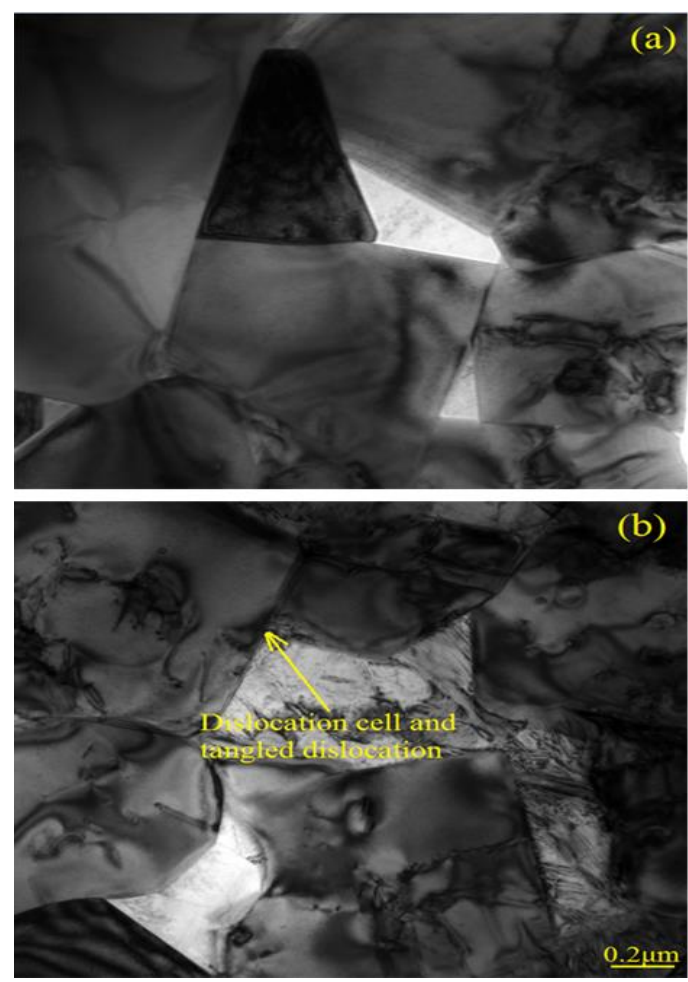

Fig.2 The TEM images of YG8:（a） untreated,

(b) pulse current treatment

\subsection{Effect of pulse current treatment on mechanical properties of cemented carbide}

By changing the different current density, the values of mechanical performance were obtained. The values were shown in Table 2. The untreated (UT) represents an untreated process.

Table 2 Mechanical performance value of different current density

\begin{tabular}{ccc}
\hline Technics & Hardness/HV & $\begin{array}{r}\text { Transverse fracture } \\
\text { strength /Mpa }\end{array}$ \\
\hline UT & 1574.40 & 1567.72 \\
PCT-A & 1585.86 & 1622.60 \\
PCT-B & 1593.32 & 1694.56 \\
PCT-C & 1608.58 & 1727.63 \\
\hline
\end{tabular}

Fig.3 showed the influence of different current density on hardness.

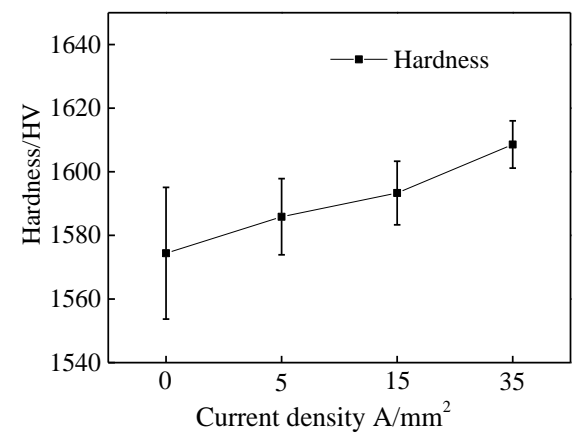

Fig.3 The effect of different current density on hardness 
It can be seen from the Fig. 3 that the hardness of the sample treated with pulse current treatment slightly higher than that untreated sample. The value of hardness was $1585.86 \mathrm{HV}, 1593.32 \mathrm{HV}$ and $1608.58 \mathrm{HV}$. Preliminary analysis may be after pulse current treatment, the structure of the material changes, the formation of high density dislocation cell and the increase of dislocation, thus the hardness is slightly increased.

Fig.4 showed the influence of different current density on transverse fracture strength.

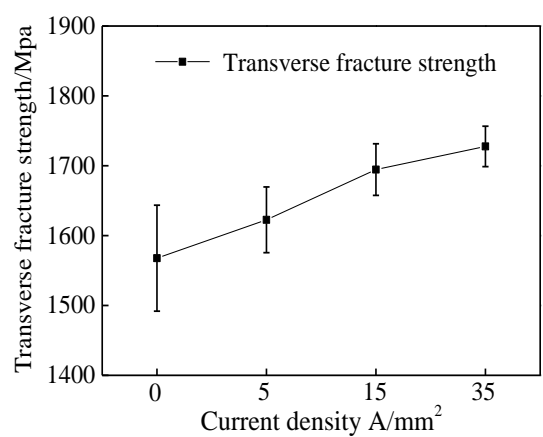

Fig.4 The effect of different current density on transverse fracture strength

It can be seen from the Fig. 4 that the transverse fracture strength of the cuboid sample was $1622.60 \mathrm{Mpa}$, 1694.56 Mpa and 1727.63 Mpa higher than that untreated sample $1567.72 \mathrm{Mpa}$, the increase value of percent was $3.5 \%, 8.1 \%$ and $10.2 \%$. After pulse current treatment, the structure of the material changes, the formation of high density dislocation cell and the increase of dislocation, thus the transverse fracture strength is slightly increased.

By changing the different current density, the tool wear was obtained, the wear curve was done nonlinear fitting by Origin software, the cutting distance of flank surface average wear value of $0.3 \mathrm{~mm}$ were obtained, the values were shown in Table 3.

Table 3 Tool cutting distance data of different current density

\begin{tabular}{cc}
\hline Technics & Cutting distance $/ \mathrm{m}$ \\
\hline UT & 112.76 \\
PCT-A & 121.38 \\
PCT-B & 122.04 \\
PCT-C & 126.32 \\
\hline
\end{tabular}

It can be seen from Table 3 that the increase percent of cutting distance for cutting tool after pulse current treatment was $5.6 \%, 8.2 \%$ and $10.8 \%$. The transverse fracture strength of material was increased after pulse current treatment, the wear of the tool decreases, while the grain refinement and structure were more evenly distributed, improving the matrix yield strength, thus improving the wear resistance performance.

Fig.5 showed the influence of pulse current treatment on the wear extent.

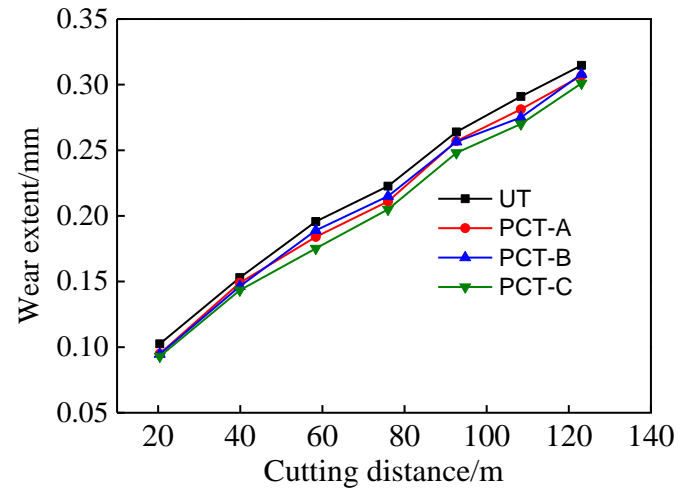

Fig.5 The effect of pulse current treatment on wear extent

It can be seen from the Fig. 5 that wear extent of the pulse current treatment tool smaller than that of the untreated tool. It may be that the transverse fracture strength and hardness of the material were improved under the action of pulse current, so the wear extent were reduced.

\subsection{Analysis of cutting force simulation}

In the process of metal cutting, the cutting force includes the main cutting force, feed force and back force. The main cutting force is to calculate the strength of the lathe, design the machine parts and determine the power of the machine tool. Therefore, the main cutting force is selected as the research object.

Fig. 6 showed the diagram of the simulation analysis of turning process in Deform-3D environment.

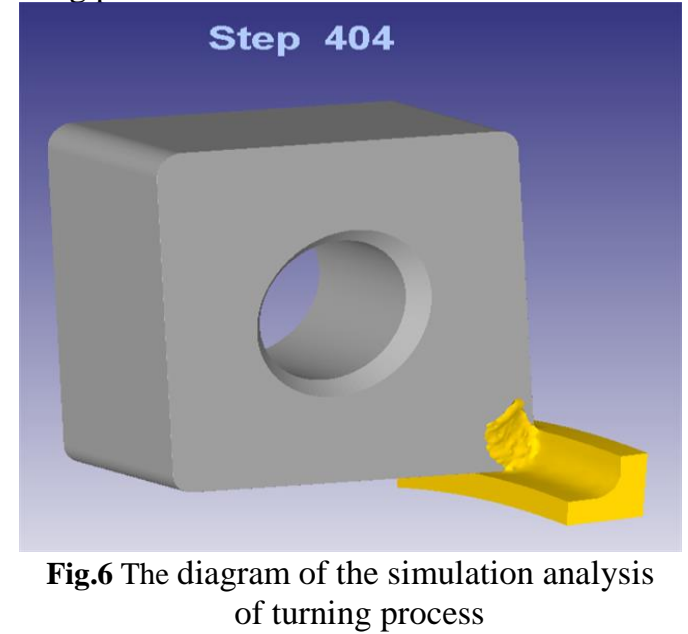

The cutting model is used to describe the machining process by using feed rate, cutting speed and depth of cut. The influence of these parameters on the machining process is analyzed by analyzing the degree of simulation and simulation results.

The orthogonal experimental parameter and numerical comparison of cutting force simulation and experimental results was shown in table 4. 
Table 4 Orthogonal experimental parameter

and simulation and experimental results

\begin{tabular}{c|c|c|c|c|c|c}
\hline Number & ap & $\mathrm{f}$ & $\mathrm{v}_{\mathrm{c}}$ & $\begin{array}{c}\text { simulation } \\
\text { values }(\mathrm{N})\end{array}$ & $\begin{array}{c}\text { experiment } \\
\text { values }(\mathrm{N})\end{array}$ & $\begin{array}{c}\text { Error } \\
(\%)\end{array}$ \\
\hline 1 & 1.2 & 0.3 & 20 & 840 & 876.7 & 4.3 \\
\hline 2 & 1.2 & 0.4 & 30 & 873 & 902.2 & 3.3 \\
\hline 3 & 1.2 & 0.5 & 40 & 902 & 925.8 & 2.6 \\
\hline 4 & 1.4 & 0.3 & 20 & 917 & 952.5 & 3.9 \\
\hline 5 & 1.4 & 0.4 & 30 & 935 & 985.2 & 5.4 \\
\hline 6 & 1.4 & 0.5 & 40 & 967 & 1015.7 & 5.0 \\
\hline 7 & 1.6 & 0.3 & 20 & 1007 & 1047.6 & 4.0 \\
\hline 8 & 1.6 & 0.4 & 30 & 1067 & 1055.6 & -1.1 \\
\hline 9 & 1.6 & 0.5 & 40 & 1076 & 1158.2 & 7.6 \\
\hline
\end{tabular}

It can be seen from Table 4 that the error is within $8 \%$, considering that the failure and friction conditions of the material in the actual cutting are very complicated, so the simulation results are acceptable. The DEFORM simulation is under ideal conditions, there are various influencing factors in actual processing, and it can be seen that there is a certain error between the simulated value of cutting force and the experimental value. But the overall error is small, within acceptable limits.

In order to verify the reliability of the cutting results obtained by simulation, the same experimental parameters are used to compare the results of the cutting force measured with the simulation results. Such as $\mathrm{a}_{\mathrm{p}}=1.2 \mathrm{~mm}, \mathrm{f}=0.3 \mathrm{~mm} / \mathrm{r}$ and $\mathrm{v}_{\mathrm{c}}=20 \mathrm{~m} / \mathrm{min}$.

Fig.7 showed the experimental curve of the cutting force measured by the dynamometer. Fig. 8 showed the 3D simulation curve of cutting force.

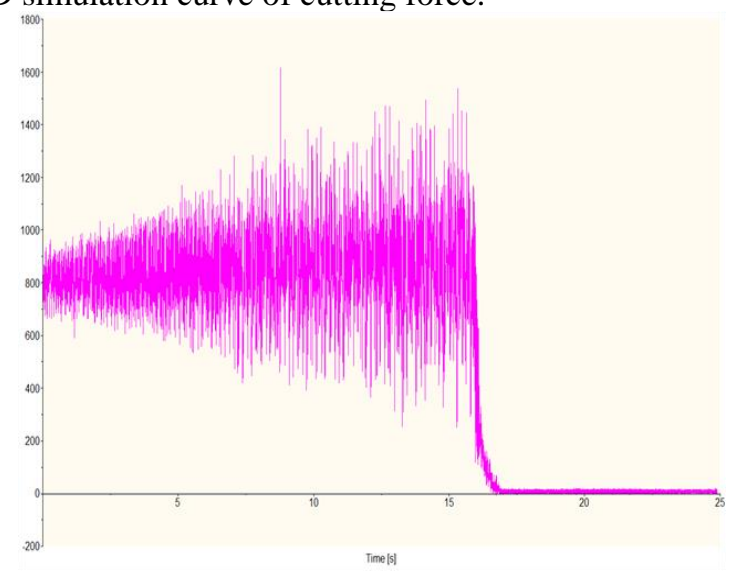

Fig.7 The experimental curve of the cutting force

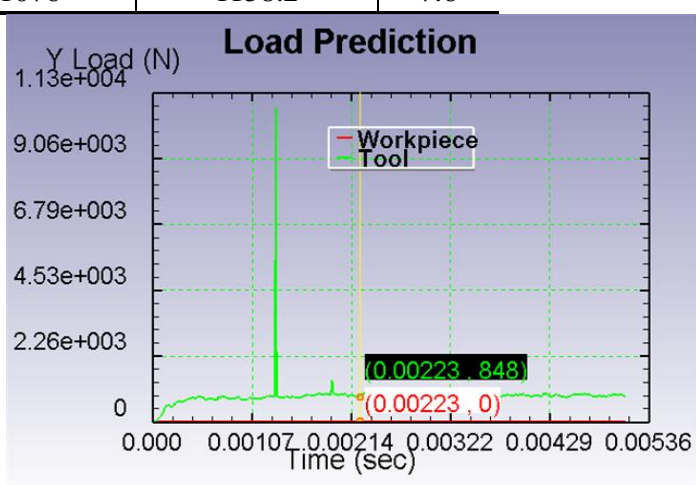

Fig.8 The 3D simulation curve of cutting force

It can be seen from the Fig.7 and Fig. 8 that when the tool cuts the workpiece, cutting force over a period of time will reach the steady value, and the value within a certain range, in the actual experiment, the image characteristics obtained by the dynamometer and software are consistent.

\section{Conclusions}

(1) This paper proposed a novel approach to improvement the properties of materials, that was: pulse current treatment. It was an important research direction and topic in the field of material processing.

(2) After the treatment of pulse current, the hardness and transverse fracture strength of sample was improved, the cutting performance also improved.

(3) Pulse current provides the driving force for dislocation motion, strong driving force is more likely to make the dislocation multiplication and slip, high density dislocation cell is formed within the material, so that the mechanical properties increase significantly.

(4) The simulation study of turning processing based on finite element analysis software Deform 3D. The size distribution of cutting force was simulated, the simulation results and the test results were compared and analyzed, which provided guiding significance for the determination of process parameters. 


\section{Acknowledgments}

Foundation item : Project (GXGZJG2017A070) supported by Guangxi Vocational Education Teaching Reform Research Project

\section{References}

1. J Xu, H Hu, W Fu, et al. Journal of Steel Research, 26, 60 (2014)

2. J Lin, $\mathrm{H}$ Zhao, Z Cai, et al. Tsinghua Univ(Sci \& Tech), 47,161 (2007)

3. Z Jiang, L Wang, L Shi, et al. Journal of mechanical engineering, 50,178 (2014)

4. Kishurov VM, Ippolitov VN, Kishurov MV. Russian Engineering Research, 32,186 (2012)

5. X Zhang, X Jie, Z Zeng, et al. Heat Treatment of Metals, 39, 53 (2014)

6. J Zhang, J Liu. Heat Treatment of Metals, 39, 132 (2014)
7. LI F, REGEL L L, WILCOX W R. Journal of Crystal Growth, 223, 251（2001）

8. BASMAK J P, SPRECHER A F, CONRAD H. Scr Metall Mater, 32, 879 (1995)

9. X Liao, Q Zhai, J Luo, et a1. Acta Materialia, 55, 3103 (2007)

10. Y Shen, X Guo, K Zhang, et al. Materials Science and Engineering, 16, 4 (1998)

11. W Zhang, M Sui, Y Zhou, et a1. Acta Metallrugica Sinica, 39, 1009 (2003)

12. B Lv, Y Zhou, B Wang, et a1. Chinese Journal of Materials Research, 17,16 (2003)

13. LEVITIN V V, LOSKUTOV S V. Solid State Communications, 131, 181（2004）

14. Y Zhou, S Luo, G He, et a1. Chinese Journal of Materials Research, 17, 169 (2003) 